\title{
Should cardiac surgery be performed in low-volume hospitals?
}

Tirone E. David, MD

See related article on page 907.

From the University of Toronto, Department of Surgery, Toronto, Ontario, Canada.

Received for publication Dec 26, 2005; accepted for publication Jan 3, 2006.

Address for reprints: Tirone E. David, MD, University of Toronto, Department of Surgery, 200 Elizabeth Street, 13EN219, Toronto, ON M5G 2C4 Canada.

J Thorac Cardiovasc Surg 2006;131:773-4 $0022-5223 / \$ 32.00$

Copyright () 2006 by The American Association for Thoracic Surgery

doi:10.1016/j.jtcvs.2006.01.004
I $\mathrm{n}$ the "Brief Communications" section of this issue of The Journal there is a report on hospital mortality after cardiac surgery in Brazil. ${ }^{1}$ An analysis of the database of the Brazilian Universal Health System, which apparently covers $75.4 \%$ of the population and more than $80 \%$ of all cardiac operations, revealed that from 2000 to 2003, 115,021 patients underwent cardiac surgery with an overall hospital mortality of $8 \%$. The hospital mortality was $6.1 \%$ for congenital heart surgery, $7 \%$ for coronary artery bypass, $8.9 \%$ for heart valve surgery, and $16.5 \%$ for "complex" operations (eg, thoracic aorta and combined procedures). Advancing age, female gender, and "complex" operations were variables associated with higher hospital mortality. The investigators also found that hospitals with annual volumes of less than 341 operations had higher mortality than those with more than 340 operations. They correctly suggested that cardiologists should be careful before recommending surgery to treat cardiovascular diseases using European and North American guidelines because the outcomes may be quite different in Brazil. They also indicated that the Brazilian Universal Health System already dictates a minimum volume and expected quality of care in hospitals in which cardiac surgery is performed. Finally, that government agency is developing a Brazilian Cardiac Surgery Registry, which will allow for more detailed analysis of clinical outcomes.

Hats off to the Brazilian Universal Health System! The mortality for cardiac surgery in some of their hospitals was found to be high, and they are doing something about it. They should also monitor individual surgeon mortality rates because hospital and surgeon mortality is often interdependent. In North America, it has been shown that low-volume hospitals may have similar operative mortality as high-volume hospitals when high-volume surgeons are responsible for coronary artery bypass operations in the low-volume hospitals. ${ }^{2}$ Thus, one may argue that high-volume surgeons may be more important than high-volume hospitals to reduce operative mortality of coronary artery bypass. There is also evidence that this is true for other cardiac operations in addition to coronary artery bypass. ${ }^{3}$

Monitoring clinical outcomes is difficult and expensive for any hospital, health care payer, or country. Although operative mortality is a crucial end point in measuring the quality of cardiac care, morbidity is also important and it has to be included in the assessment of quality. Operative mortality usually parallels operative morbidity, and consequently, increased cost to the payer. The experience with monitoring outcomes in cardiac surgery is quite extensive, and there are now several useful quality indicators for congenital and coronary artery surgery. In Ontario, where there is a universal health care insurance, cardiac surgery is highly regulated and performed only in hospitals approved by the Ministry of Health. All cardiac units have annual volumes of more than 500 operations, and most surgeons perform more than 200. Consequently, operative mortality for routine procedures such as coronary artery bypass is very low, and other outcomes such as myocardial infarction, stroke, wound infections, blood transfusion, chest reopening, intensive care readmission, length of stay, and repeat interventions within the first year are now being introduced in the assessment of quality of health care. ${ }^{4}$ However, quality and appropriateness of care are more difficult to measure for operations for heart valve disease, aortic root aneurysm, transverse arch and thoracic aortic aneurysms, acute aortic dissection, active infective endocarditis, mechanical complications of myocardial infarction, end-stage congestive heart failure, cardiac tumors, and others. 
The explosion in the number of coronary artery bypass operations during the 1980s and 1990s stimulated the opening of cardiac surgical units everywhere. However, the first 5 years of the new millennium showed a decline in the number of patients who required coronary artery bypass and a small increase in the number of patients who required surgery for heart valve disease and end-stage heart failure. These changes are forcing surgeons to acquire new expertises, and health care regulators to develop new methodology to assess clinical outcomes. The measurement of quality in these areas is far more difficult than in coronary artery surgery because the patients and their clinical presentation, and the pathology are more heterogeneous, and the numbers of the various subsets of patients are much smaller.

These changes in the management of cardiovascular diseases coupled with the public and government demands for quality and appropriateness of care will make it increasingly more difficult for surgeons and hospitals to justify poor clinical outcomes. I believe that recentralization of special- ized cardiac care will be inevitable, and that we, in turn, will have to work together in large units to develop the expertise required to look after patients with more complicated cardiovascular problems and optimize the quality of their care. Patients may protest about traveling longer distances to receive specialized services, but they will stand to gain by having experts to look after their health.

\section{References}

1. Ribeiro ALP, Gagliardi SPL, Nogueira JLS, Silveira LM, Colosimo EA, Nascimento CAL. Mortality related to cardiac surgery in Brazil, 20002003. J Thorac Cardiovasc Surg. 2006;131:907-9.

2. Zacharias A, Schwann TA, Riodan CJ, et al. Is hospital procedure volume a reliable marker of quality for coronary artery bypass surgery? A comparison of risk and propensity adjusted operative and midterm outcomes. Ann Thorac Surg. 2005;79:1961-9.

3. Birkmeier JD, Stukel TA, Siewers AE, Goodney PP, Wennberg DE, Lucas FL. Surgeon volume and operative mortality in the United States. $N$ Engl J Med. 2003;349:2117-27.

4. Guru V, Anderson GM, Fremes SE, et al. The identification and development of Canadian coronary artery bypass graft surgery quality indicators. J Thorac Cardiovasc Surg. 2005;130:1257-64.

To assure fairness to authors submitting work for consideration in The Journal of Thoracic and Cardiovascular Surgery, a mechanism exists for managing conflicts of interest. The editor and each of the section editors complete a "Conflict of Interest" form that identifies any and all relationships with commercial and other academic entities. When the editor has a potential conflict because of a relationship with another entity or author, the editor appoints an alternate editor from among the section editors or editorial board members who assumes the entire responsibility for final decisions on the manuscript in question. The editor does not read the reviews that are submitted nor engage in discussing the manuscript prior to the final decision. When the conflict of interest involves a section editor, a "guest section editor" is appointed who fills the role normally played by the conflicted section editor. All members of the editorial board and reviewers are asked to indicate any conflict of interest when they agree to review a manuscript. 